\title{
IV. Sumarios de otras revistas
}




\section{REVISTA DE ADMINISTRACIÓN PÚBLICA}

Director: Eduardo García de Enterría

Secretaria: Carmen Chinchilla Marín

Sumario del número 169

(Enero-Abril 2006)

\section{ESTUDIOS}

- F. A. CASTILLO BLANCO: Público y privado en la defensa del espacio urbano: hacia una necesaria revisión del sistema reaccional vigente.

- J. ORTEGA BERNARDO: Competencias, servicios públicos y actividad económica de los municipios.

- G. G. RUIZ ZAPATERO: Los efectos de las leyes tributarias inconstitucionales.

\section{JURISPRUDENCIA}

i. COMENTARIOS MONOGRÁFICOS

- G. GARCÍA ÁLVAREZ: La modulación de la responsabilidad de la Administración en determinados casos de ejercicio ilegal de potestades urbanísticas.

- M. GARCÍA PÉREZ: La indeterminación del dominio públixo marítimo-terrestre en la Ley de Costas de 1988. A propósito del deslinde de acantilados.

II. NOTAS DE JURISPRUDENCIA CONTENCIOSO-ADMINISTRATIVA

- T. FONT i LLOVET, A. GALÁN GALÁN, O. MIR PUIGPELAT y J. TORNOS MAS.

- O. BOUAZZA ARIÑO: Notas de Jurisprudencia del Tribunal Europeo de Derechos Humanos.

\section{CRÓNICA ADMINISTRATIVA}

\section{ESPAÑOLA Y COMUNITARIA}

- J. M. DÍAZ LEMA: Bases para la construcción de un Derecho de aguas europeo.

- A. FANLO LORAS: Planificación hidrológica en España: estado actual de un modelo a fortalecer.

- N. DE MIGUEL SÁNCHEZ: El derecho a la protección de datos personales en el Tratado por el que se instituye una Constitución para Europa.

- J. L. PALMA FERNÁNDEZ: El contrato de transacción y las Administraciones Públicas. La doctrina del Consejo de Estado.

- A. J. SÁNCHEZ NAVARRO: La función constitucional del Consejo de Estado tras su reforma por la Ley Orgánica 3/2004.

II. EXTRANJERA

- I. GALLEGO CÓRCOLES: El procedimiento de expropiación italiano: entre la irrelevancia de las formas y la intervención correctora del TEDH.

- J. GONZÁLEZ PÉREZ: La nueva Ley Federal mexicana reguladora del procedimiento contencioso-administrativo.

\section{DOCUMENTOS Y DICTÁMENES}

- A. EMBID IRUJO: La sentencia del Tribunal Supremo de 20 de octubre de 2004 en relación a las cuencas internas de las Comunidades Autónomas Valenciana y de Castilla-La Mancha desde la perspectiva de su ejecución y cumplimiento.

\section{BIBLIOGRAFÍA}

\section{RECENSIONES}

PRECIOS AÑO 2006

\begin{tabular}{|c|c|c|c|}
\hline \multicolumn{2}{|c|}{ NÚMERO SUELTO } & SUSCRIPCIÓN ANUAL \\
\hline España & Extranjero & España & Extranjero \\
\hline $18,00 €$ & $25,00 €$ & $51,00 €$ & $74,00 €$ \\
\hline Números 1-162 (Años 1950-2003), presentados en DVD: $250 €$ \\
y en CD-ROM: $250 €$ \\
Suscriptores $20 \%$ descuento (I.V.A. incluido)
\end{tabular}

Suscripciones, venta directa y pedidos por correo de números sueltos: CENTRO DE ESTUDIOS POLÍTICOS Y CONSTITUCIONALES

San Francisco de Sales, 6 - 28071 MADRID

Tf.: (34) $914412700 \quad$ FAX: (34) 914410086

E-mail: distribrev@cepc.es 


\section{ADMINISTRACIÓN DE ANDALUCÍA Revista Andaluza de Administración Pública}

\begin{tabular}{|c|c|}
\hline & N. ${ }^{\circ} 59$ \\
\hline & Julio-Agosto-Septiembre 2005 \\
\hline \multirow[t]{4}{*}{ ESTUDIOS } & \\
\hline & $\begin{array}{l}\text { José Luis Rivero Ysern } \\
\text { Reflexiones sobre la Gobernanza Europea. }\end{array}$ \\
\hline & $\begin{array}{l}\text { Juan Antonio Carrillo Donaire } \\
\text { La intervención administrativa sobre las vías pecuarias. }\end{array}$ \\
\hline & $\begin{array}{r}\text { Eloísa María Pérez Andrés } \\
\text { El deslinde de las vías pecuarias y su control judicial. }\end{array}$ \\
\hline
\end{tabular}

\section{JURISPRUDENCIA}

\section{Comentarios de Jurisprudencia}

La legitimación de los miembros de las corporaciones locales para impugnar los acto y acuerdos de las mismas. (Comentario a la STC 173/2004, de 28 de octubre)

(Luis Enrique Flores Domínguez)

\section{Notas de Jurisprudencia}

Tribunal Constitucional

I. Constitución.-II. Derechos y Libertades.-III. Principios Jurídicos Básicos.-IV. Instituciones del Estado.-V. Fuentes. VI. Organización Territorial del Estado.-VII. Economía y Hacienda.

(Francisco Escribano López)

Tribunal Supremo y Tribunal Superior de Justicia de Andalucía

I. Acto Administrativo.-II. Administración Local.III. Administración Pública.-IV. Bienes Públicos.V. Comunidades Autónomas.-VI. Contratos.VII. Corporaciones de Derecho Público.VIII. Cultura, Educación, Patrimonio Histórico.-

IX. Derecho Administrativo Económico.$X$. Derecho Administrativo Sancionador.XI. Derechos Fundamentales y Libertades.XII. Expropiación Forzosa.-XIII. Fuentes.XIV. Hacienda Pública.-XV. Jurisdicción ContenciosoAdministrativa.-XVI. Medio Ambiente.-XVII. Organización.- 


XX. Responsabilidad.-XXI. Salud y Servicios Sociales.-
XXII. Urbanismo y Vivienda.-
Tribunal Supremo (José I. López González)
Tribunal Superior de Justicia de Andalucía
(José L. Rivero Ysern)




\title{
Revista de Estudios de la Administración Local y Autonómica
}

\author{
300-301 : ENERO - AGOSTO 2006
}

MINISTERIO

DEADMINISTRACIONES

PÚBLICAS

\section{Presentación: Francisco RAMOS FERNÁNDEZ-TORRECILLA}

\section{Estudios}

Luis MORELL OCAÑA: La dinámica provincial a partir de la Constitución.

Luis ORTEGA: El Régimen Local y Estatutos de Autonomía.

Ángel SÁNCHEZ BLANCO:Administración Local y sistema Administrativo. La interrelación procedimental y telemática de registro, archivo y secretaria.

Elisenda MALARET: Municipios, democracia cosmopolita y cooperación al desarrollo descentralizada.

Miguel DOMINGUEZ-BERRUETA DE JUAN:Anotaciones básicas sobre la Administración Local de Castilla y León.

Armando RODRIGUEZ GARCÍA: Potencialidad del contencioso administrativo en la eficiencia y modernización de los servicios públicos. Jaime RODRIGUEZ-ARANA: Modelo territorial y principio de cooperación.

José SUAY RINCÓN: Sobre los Cabildos Insulares y su caracterización institucional.

José Manuel DÍAZ LEMA: El interés supralocal como medida del control sobre las entidades locales. En especial, en el ámbito urbanístico.

Antonio CALONGEVELÁZQUEZ: El Comité de las Regiones en el futuro de Europa.

Dionisio FERNÁNDEZ DE GATTA SÁNCHEZ: El régimen jurídico de la prevención ambiental en la Comunidad de Castilla y León.

Marc VILALTA REIXACH: Nuevas formas de cooperación territorial: las organizaciones asociativas de entes locales.

Enrique ORDUÑA REBOLLO: La Unión de Municipios Españoles, antecedentes y evolución del municipalismo asociativo.

María Dolores CALVO SÁNCHEZ: Protección de datos personales a través del secreto profesional en el ámbito de la Administración Sanitaria Local.

Ricardo RIVERO: Problemas administrativos en los nuevos espacios metropolitanos: la ausencia de una respuesta normativa suficiente en la Comunidad Autónoma de Castilla y León.

José VIDA FERNÁNDEZ: La intervención municipal sobre la distribución gratuita de prensa en la via pública.

Maria José FERNÁNDEZ PAVÉS y Antonia JABALERA RODRIGUEZ: Poder tributario local y reserva de ley ante la próxima reforma del Gobierno Local.

Juan Francisco PÉREZ GÁLVEZ: La comercialización de los juegos de la ONCE y su incidencia en el ámbito autonómico y local.

Valentin MERINO ESTRADA: Las nuevas Ordenanzas municipales reguladoras de la convivencia ciudadana.

Francisco LÓPEZ MERINO: Naturaleza del documento de formalización de los contratos de los entes locales.

Jurisprudencia

Carlos ROMERO REY: Últimos pronunciamientos jurisprudenciales en materia de responsabilidad patrimonial de interés para las entidades locales. $M^{2}$ Dolores REGO BLANCO:Ante la inactividad local ¿sustitución, acción popular o contencioso interadministrativo? Reflexiones a propósito de la protección de la legalidad urbanistica.

Ángel BALLESTEROS FERNÁNDEZ: La responsabilidad patrimonial de los entes instrumentales de la Administración y la entidad matriz. Recensiones

Sumarios de otras revistas 